\title{
Guided Growth of Horizontal p-type ZnTe
}

Nanowires

Gilad Reut,,$^{\dagger}$ Eitan Oksenberg, ${ }^{\dagger}$ Ronit Popovitz-Biro, ${ }^{+}$Katya Rechav, ${ }^{+}$and Ernesto Joselevich ${ }^{\dagger}, *$

${ }^{\dagger}$ Department of Materials and Interfaces and ${ }^{\ddagger}$ Chemical Research Support, Weizmann Institute

of Science, Rehovot 76100, Israel

\section{Supporting Information}


Table S1- Crystallographic orientations of guided nanowires on different planes of sapphire

\begin{tabular}{|c|c|c|c|}
\hline Substrate & \# of NWs & $\begin{array}{c}\text { Crystal } \\
\text { Structure }\end{array}$ & $\begin{array}{l}\text { Axial Orientation } \\
\qquad \mathrm{ZnTe} \| \mathrm{Al}_{2} \mathrm{O}_{3}\end{array}$ \\
\hline \multirow[b]{4}{*}{ Annealed M-plane } & 1 & $\mathrm{WZ}$ & {$[0001] \|[1 \overline{2} 10]$} \\
\hline & 2 & ZB & {$[\overline{1} 12]^{*} \|[1 \overline{2} 10]$} \\
\hline & 3 & ZB & {$[100] \|[1 \overline{2} 10]$} \\
\hline & 1 & ZB & {$[1 \overline{1} 0] \|[1 \overline{2} 10]$} \\
\hline \multirow[t]{2}{*}{$(10 \overline{1} 0)$} & 1 & ZB & {$[1 \overline{1} 1] \|[1 \overline{2} 10]$} \\
\hline & 1 & $\mathrm{WZ}$ & {$[30 \overline{3} 1] \|[1 \overline{2} 10]$} \\
\hline M-plane $(10 \overline{1} 0)$ & 3 & ZB & {$[1 \overline{1} 0] \|[1 \overline{2} 10]$} \\
\hline $\begin{array}{l}\text { C-plane } \\
(0001)\end{array}$ & 9 & ZB & {$[\overline{1} 12]^{*} \|[10 \overline{1} 0]$} \\
\hline $\begin{array}{l}\text { Annealed vicinal C-plane } \\
\qquad(0001)\end{array}$ & 3 & ZB & {$[\overline{1} 12]^{*} \|[10 \overline{1} 0]$} \\
\hline
\end{tabular}

*The ZB [ $\overline{1} 12]$ growth axis and the WZ [10 $\overline{1} 0]$ of ZnTe have a very similar diffraction cannot be distinguished using our attained data. Since ZnTe is almost always found to be in the ZB crystal phase, the ZB [ $\overline{1} 12]$ is considered the growth direction of the nanowires. 
Table S2. Mismatch between $\mathrm{ZnTe}$ and $\mathrm{Al}_{2} \mathrm{O}_{3}$ along and across the nanowires on different planes of sapphire

\begin{tabular}{|c|c|c|c|c|c|c|}
\hline \multirow{2}{*}{$\begin{array}{c}\text { Axial } \\
\text { Orientation } \\
\mathrm{ZnTe} \| \mathrm{Al}_{2} \mathbf{O}_{3}\end{array}$} & \multicolumn{3}{|c|}{ Longitudinal } & \multicolumn{3}{|c|}{ Transversal } \\
\hline & $\begin{array}{c}a_{0}[\AA ̊ \AA] \\
\text { ZnTe: } \mathbf{A l}_{\mathbf{2}} \mathbf{O}\end{array}$ & $\begin{array}{c}\text { Ratio } \\
\text { ZnTe: } \mathrm{Al}_{2} \mathrm{O}\end{array}$ & $\begin{array}{c}\text { Mismatch } \\
{[\%]}\end{array}$ & $\begin{array}{c}a_{0}[\mathbf{\AA}] \\
\text { ZnTe: } \mathbf{A l}_{2} \mathbf{O}\end{array}$ & $\begin{array}{c}\text { Ratio } \\
\text { ZnTe: } \mathrm{Al}_{2} \mathrm{O}\end{array}$ & $\begin{array}{c}\text { Mismatch } \\
{[\%]}\end{array}$ \\
\hline $\multirow[t]{2}{*}{112} \|\{10 \overline{1} 0\}$ & $2.492: 4.122$ & $1: 1$ & 39.54 & $4.318: 2.381$ & $1: 1$ & 81.35 \\
\hline & & $3: 2$ & 9.32 & & $1: 2$ & 9.32 \\
\hline $\multirow[t]{2}{*}{110} \|\{1 \overline{2} 10\}$ & $4.318: 2.381$ & $1: 1$ & 81.35 & $3.525: 2.552$ & $1: 1$ & 38.13 \\
\hline & & $1: 2$ & 9.32 & & $3: 4$ & 3.59 \\
\hline
\end{tabular}

The mismatch is the calculated using equation (S1), where $a_{0}\left(\mathrm{Al}_{2} \mathrm{O}_{3}\right)$ is the bulk lattice parameter of the relevant sapphire planes and $a_{0}(Z n T e)$ is the bulk lattice parameter of the relevant ZnTe planes. The mismatch is calculated for 1:1 ratio, and also for other ratios, where such a ratio improves the coincidence lattice matching.

(S1) Mismatch [\%] $=\frac{\left|a_{0}\left(A l_{2} O_{3}\right)-a_{0}(\mathrm{ZnTe})\right|}{a_{0}\left(A l_{2} \mathrm{O}_{3}\right)}$ 
Table S3. TEM EDS results of two ZnTe nanowires on annealed M-plane sapphire

\begin{tabular}{|c|c|c|c|c|}
\hline & \multicolumn{2}{|c|}{ Nanowire 1 } & \multicolumn{2}{c|}{ Nanowire 2 } \\
\hline Element & Te & Zn & Te & Zn \\
\hline Weight \% & 67.8 & 32.2 & 68.6 & 31.4 \\
\hline Atomic \% & 51.9 & 48.1 & 52.8 & 47.2 \\
\hline Uncet \% & 0.75 & .250 & 1.17 & 0.39 \\
\hline
\end{tabular}

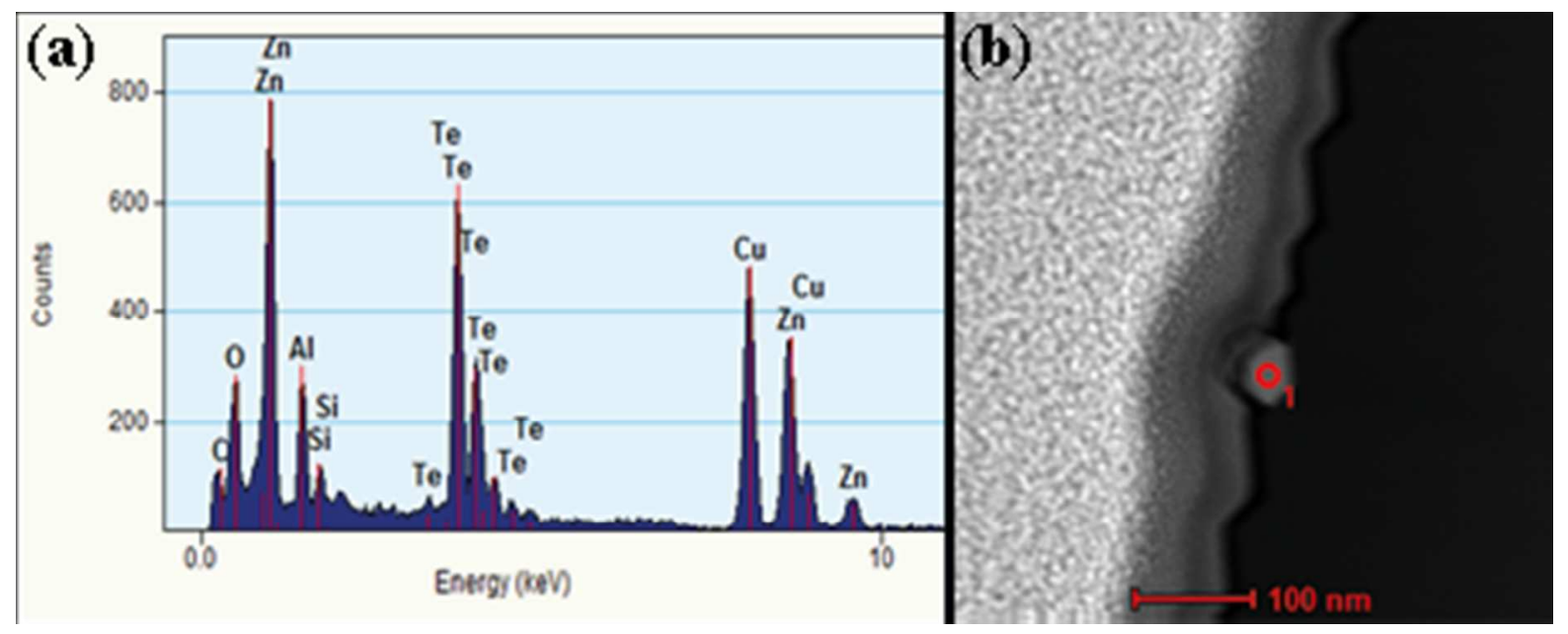

(b)

Figure S1. TEM EDS spectrum of ZnTe nanowire grown on annealed M-plane sapphire. (a) The TEM EDS spectrum. (b) TEM cross-section image of the measured nanowire. 


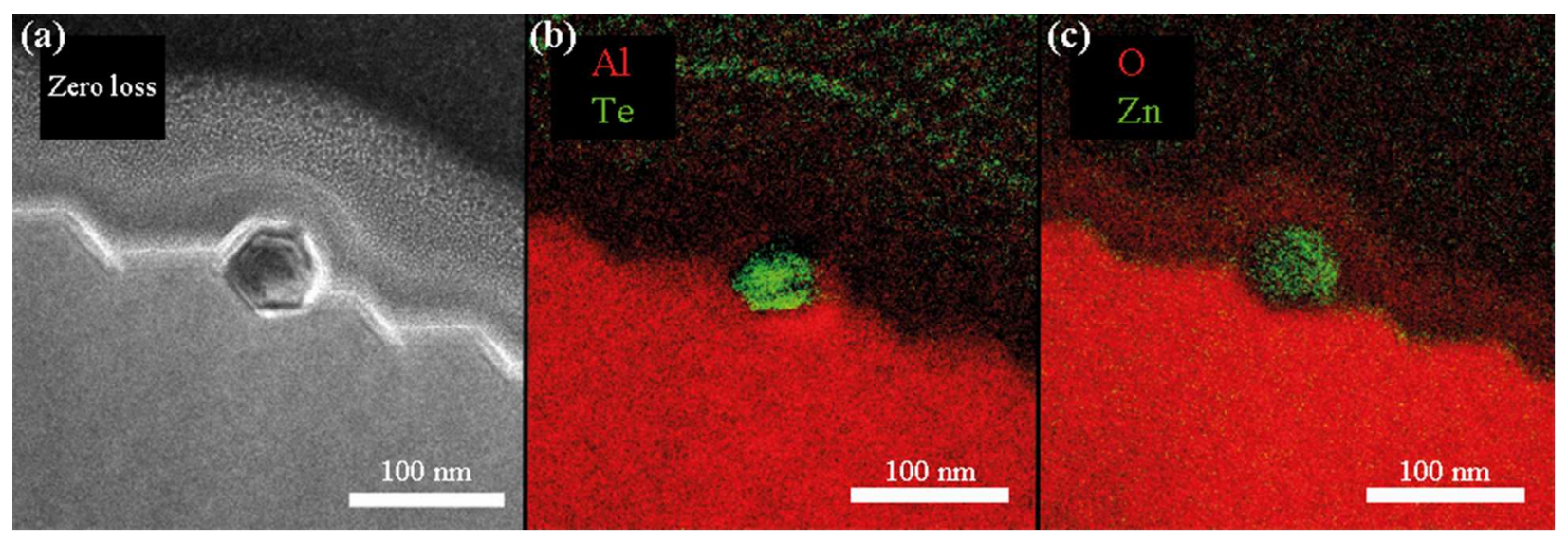

Figure S2. EFTEM elemental map analysis of a guided ZnTe nanowire on annealed M-plane sapphire: (a) Zero loss image. (b) Te (green) and $\mathrm{Al}$ (red). (c) $\mathrm{Zn}$ (green) and $\mathrm{O}$ (red). 